\title{
Basal versus Apical Dendritic Long-Term Potentiation of Commissural Afferents to Hippocampal CA1: A Current-Source Density Study
}

\author{
Taro Kaibara and L. Stan Leung \\ Departments of Physiology and Clinical Neurological Sciences, The University of Western Ontario, London, Canada N6A \\ 5 A5
}

Current-source density analysis was used to estimate the magnitude of the synaptic excitation at the basal and apical dendritic synapses of CA1 following commissural stimulation in the urethane-anesthetized rat, before and after $a \theta$-frequency patterned primed burst tetanus. Stimulation of the contralateral CA3 or the contralateral CA1 stratum oriens excited both the basal and apical dendrites in CA1 about equally. However, primed burst tetanization of the contralateral CA3 or CA1 stratum oriens resulted in significant long-term potentiation (LTP) only at the basal dendrites and not at the apical dendrites. Stimulation of the contralateral CA1 stratum radiatum excited the apical dendrites more than the basal dendrites of CA1, but tetanization of this contralateral site gave little change in the apical or basal dendritic excitation. Tetanization of the contralateral CA1 stratum radiatum after an intraventricular administration of bicuculline, a GABA antagonist, however, resulted in significant LTP at both the apical and basal dendrites. It was concluded that, in the intact hippocampus in vivo, the threshold for LTP at the commissural apical dendritic synapse was high in comparison to that at the basal dendritic synapse and this high threshold may be partly caused by inhibitory interneurons that predominantly synapsed on the apical dendrites. Thus, the basal and apical dendrites of the CA1 pyramidal cells are not equal In their propensity for long-term plastlclty.

IKey words: CA1, CA3, apical dendrites, basal dendrites, long-term potentiation, inhibition, hippocampal commissure]

A long-lasting increase in synaptic response known as long-term potentiation (LTP) occurs following a brief, high-frequency stimulus to an afferent pathway. LTP has been observed at many different synapses in the brain (Teyler and Discenna, 1987) and has been implicated as a substrate for memory. The conditions for the induction and maintenance of LTP havc been extensively examined in vitro, especially in brain slices (Madison et al., 1991).

LTP was first discovered in vivo, at the perforant path to the dentate gyrus synapse (Bliss and Lomo, 1973). Since then, different properties of LTP were found for various afferents to the

Received July 29, 1992; revised Nov. 25, 1992; accepted Dec. 8, 1992.

We thank B. Shen and L. Roth for technical assistance, and Dr. C. Y. Yim for programming. This work was supported by NSERC Grant A1037.

Correspondence should be addressed to Dr. L. S. Leung, Department of Clinical Neurological Sciences, University Hospital 10th Floor, The University of Western Ontario, London, Canada N6A 5A5.

Copyright $@ 1993$ Society for Neuroscience $0270-6474 / 93 / 132391-14 \$ 05.00 / 0$ dentate gyrus, including the medial and the lateral perforant path and the commissural inpul (Levy and Steward, 1979; McNaughton, 1980; Douglas et al., 1982; Abraham et al., 1985; Levy and Desmond, 1985; Steward et al., 1990). The properties of LTP was also found to be different at the commissural synapse as compared to the mossy fiber synapse in CA3 (Chattarji et al., 1989; Zalutsky and Nicoll, 1990). In contrast, differential properties of LTP at different synapses in CA1 have not been systematically studied. The pyramidal cells of CAl possess two distinct dendritic trees, the apical and the basal dendrites, each receiving afferent inputs from $\mathrm{CA} 3$ through the commissural and the associational (Schaffer collateral) fibers (Blackstad, 1956; Swanson et al., 1978; Frotscher, 1983; Tamamaki et al., 1988; Ishizuka et al., 1990). In addition, septal and perforant path inputs synapse at restricted layers in CA1 (Raisman et al., 1965; Yeckel and Berger, 1991). The many laminated afferent inputs to CAl suggest possibilities of a rich interaction of synaptic inputs and plasticity.

Studies of LTP in the hippocampal slice in vitro seem to suggest that the basal and apical dendritic synapses showed equal propensity for an input-specific LTP (Andersen et al., 1980; Sastry et al., 1986). Commissural afferents were known to be effective in evoking LTP (Buzsaki, 1980; Bliss et al., 1983; Diamond et al., 1988), but differences between apical dendritic versus basal dendritic LTP in CA1 have not been reported. Using field potential recordings in freely behaving rats, we showed that the commissural basal dendritic synapse exhibited a consistently more robust and larger LTP than the apical dendritic synapse (Leung et al., 1992), though apical dendritic LTP could be found under some conditions (Staubli and Lynch, 1987; Leung and Shen, 1991; Leung et al., 1992). In all of the in vivo studies, LTP was shown as an enhancement of the field potential. Field potentials are, by definition, generated by field currents that consisted of both local and distant (volume-conducted) components (Leung, 1990). When multiple synapses are activated, an enhancement of a field potential may be interpreted as either an enhancement of the local currents or a decrease or change of the distant, volume-conducted currents. Thus, a quantitative assessment of LTP should use the increase in local synaptic current density.

Current-source density (CSD) analysis reveals the amount of current moving out of (source) or into (sink) the intracellular medium (Freeman and Nicholson, 1975; Leung, 1990). An apical dendritic EPSP will give an active sink in stratum radiatum, and a basal dendritic EPSP will give a sink in stratum oriens. In this article, CSD analysis was used to study the change in 


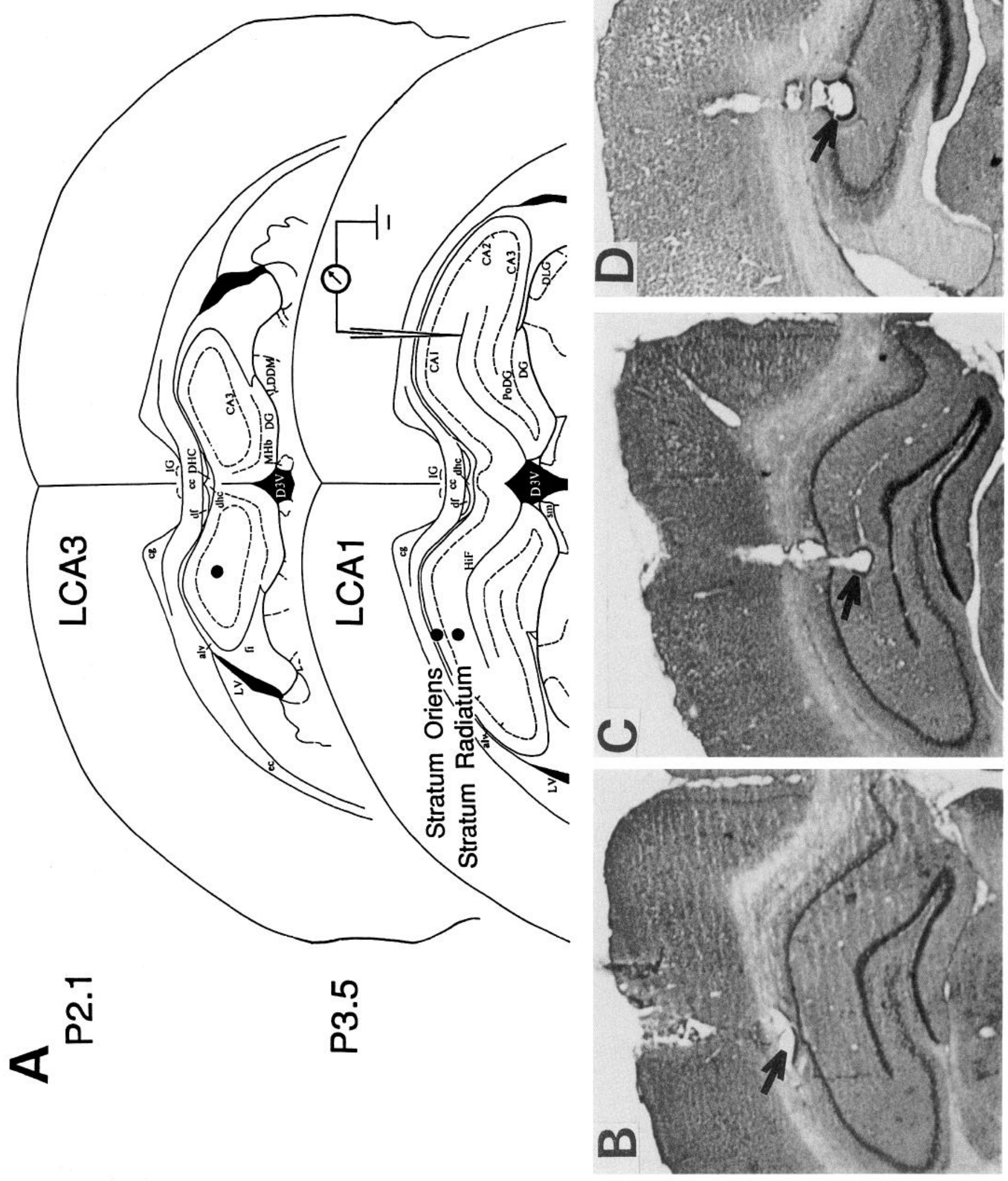


the different dendritic sinks in CA1 following tetanization of various sets of commissural inputs to CA1. It is known that stimulation of the CAl led to antidromic firing of CA3 cells (Buzsaki and Eidelberg, 1982a) and excited the homotopic contralateral CA1 (Andersen, 1960). It was further found that stimulation of stratum oriens and stratum radiatum of $\mathrm{CA} 1$ resulted in different ratios of basal versus apical dendritic excitation of the contralateral CA1 (Leung et al., 1992). Thus, in addition to CA3 stimulation, a subset of the commissural input was activated by stimulation of stratum oriens or stratum radiatum of the contralateral CAI. The anesthetized rat was used because of its stability for sequential potential field mapping.

\section{Materials and Methods}

Male hooded rats weighing between 250 and $350 \mathrm{gm}$ were anesthetized with $1.2 \mathrm{gm} / \mathrm{kg}$ urethane intraperitoneally and placed in a stereotaxic apparatus. Animal body temperature was maintained between $36^{\circ} \mathrm{C}$ and $37^{\circ} \mathrm{C}$ via a rectal thermistor probe and heating pad.

One to three stimulating electrodes $(125 \mu \mathrm{m}$ Teflon-insulated steel wires) were placed at (1) anterior left CA3 (LCA3) at P2.1, L1.7, 3.1 mm below the skull surface; (2) left CA1 (LCA1) stratum oriens at P3.5, $\mathrm{L} 2.7,2.8 \mathrm{~mm}$ below the skull surface; and (3) LCAl stratum radiatum at P3.5, L2.7, 3.2 $\mathrm{mm}$ below the skull surface (Fig. 1). The three stimulus sites served to activate the basal and apical dendrites of the contralateral CAI in different proportions (Buzsaki and Eidelberg, 1982a; Leung et al., 1992). The depth of the stimulus electrode was optimized by slight $(<0.1 \mathrm{~mm})$ movements, monitored to evoke the largest responses. Photoisolated constant-current pulses of $0.2 \mathrm{msec}$ duration were delivered cathodally to one of the three sites at $<0.2 \mathrm{~Hz}$ repetition rate. A screw in the frontal skull served as the stimulus anode.

Extracellular potentials were recorded with reference to a cerebellar screw using 4-12 M $\Omega$ glass micropipettes filled with $2 \mathrm{M}$ sodium acetate and $4 \%$ pontamine sky blue. The electrode was mounted on a Burleigh 6000 Inchworm Microdrive ( $1 \mu \mathrm{m}$ step resolution). Spatial coordinates were with respect to bregma, and in most experiments, the track through the right CA1 was at P3.5, L2.7. The extracellular field potentials were amplified and bandpass filtered at $0.1-2 \mathrm{kHz}$ using an Axoclamp-2A amplifier and an Intronix 20004-F signal conditioner. The sweeps were displayed on an oscilloscope, digitized at $10 \mathrm{kHz}$, and averaged (typically eight sweeps) to give averaged evoked potentials (AEPs) using a custom program on an IBM AT-compatible computer. Paired pulses at 30-50 msec interpulse intervals were delivered at just above threshold to each of the three stimulus sites; it is known that homosynaptic but not heterosynaptic paired-pulses showed presynaptic facilitation (Lomo, 1971; Muller and Lynch, 1989). A laminar profile was then recorded in the right CA1 (P3.5, L2.7) at $50 \mu \mathrm{m}$ depth intervals, typically in 20 steps, in a deep-to-surface direction using single pulses applied at two times the visually detectable threshold of each stimulus. Pilot and post hoc input-output data indicated that LTP was not significantly different at various test stimulus intensities. A laminar profile required approximately 20-30 min to complete. The recording electrode was then fixed at the site of maximal positive field potential (presumed CAl cell layer; see below), and AEPs were recorded for a $20 \mathrm{~min}$ baseline period prior to tetanization. A tetanus of suprathreshold intensity $(400-600 \mu \mathrm{A}, 0.2$ msec pulses to ensure maximal LTP) consisted of eight patterned primed bursts, at 10 sec intervals, with each primed burst consisting of a single pulse followed $190 \mathrm{msec}$ later by 10 pulses at $100 \mathrm{~Hz}$. The patterned primed burst presumably reproduced CA 3 pyramidal cell complex spike burst (spike interval within burst at $10 \mathrm{msec}$ ) modulated at a theta frequency (Ranck, 1973; Buzsaki et al., 1983). Primed bursts were shown to be effective in eliciting LTP in the CA1 region without evoking afterdischarges (Diamond et al., 1988; Leung et al., 1992). After tetanization, AEPs at the CA1 cell layer were recorded for up to $60 \mathrm{~min}$. At 30-60 min after tetanus, when the cell layer AEP was rather stable, another deep-to-surface laminar profile was recorded. For any given experiment, only one single site was tetanized but pre- and posttetanus laminar profiles were recorded for all stimulus sites. In order to minimize electrode movement, responses from different stimulus sites were recorded at a fixed depth.

One-dimensional (depth z) current-source densities (CSDs) were calculated from the laminar profile of AEPs. The currents in the $x$ - and $y$-directions were assumed to be negligible (Leung, 1979), as was expected from the extensive divergence of the commissural input (Swanson et al., 1978), and supported by data in two rats in which AEPs were mapped in multiple (z-direction) tracks in the frontal plane (not shown). The one-dimensional CSDs were calculated using the formula

$$
C S D(z)=\frac{[2 \Phi(z)-\Phi(z+2 \Delta z)-\Phi(z-2 \Delta z)] \sigma_{z}}{(2 \Delta z)^{2}},
$$

where $\operatorname{CSD}(z)$ is the CSD at depth $z, \Phi(z)$ is the AEP at depth $z, \Delta z$ is the depth interval $(50 \mu \mathrm{m})$, and $\sigma_{z}$ is the conductivity in the z-direction.

The above CSD formula (a second-order differencing using $100 \mu \mathrm{m}$ intervals) is equivalent to first smoothing the AEPs at every $50 \mu \mathrm{m}$ interval with scaling factors $(1 / 4,1 / 2,1 / 4)$ over three depths (Freeman and Nicholson, 1975; Leung, 1990), and then obtaining CSDs at each $50 \mu \mathrm{m}$ interval. It was among the simplest formula that effectively reduced the noise of the CSDs (Freeman and Nicholson, 1975). Conductivity in the CA1 region was not measured here. Although the conductivity was reported to be lower in the pyramidal cell layer than in the dendritic layers, the assumption of homogeneous conductivity only incurred a small error in the calculated CSDs (Holsheimer, 1987; confirmed in vivo by W. Wadman, L. S. Leung, and F. H. Lopes da Silva, unpublished observations). Thus, $\sigma_{z}$ was assumed to be constant and the CSDs were calculated in arbitrary units $\left(\mathrm{mV} / \mathrm{mm}^{2}\right)$, proportional to the actual current densities. The integrated (total) size of the current sinks at the basal or apical dendrites was quantified by summing the CSDs in stratum oriens (typically over $100 \mu \mathrm{m}$ ) or stratum radiatum (typically over $200 \mu \mathrm{m}$ ). An apical-to-basal dendritic sink ratio was defined as the ratio of the integrated size of the sink at the apical dendrites to that at the basal dendrites.

The stability of the preparation to repeated laminar profile recordings was studied in four control animals. The "pretetanus" (first) and "posttetanus" (second) laminar profiles were recorded as in experimental animals, with the tetanus substituted with 88 pulses applied at $0.1 \mathrm{~Hz}$. Little change was observed in the AEPs and CSDs after the 88 pulses (Fig. 2). The total basal and apical dendritic sinks after the 88 pulses were $100 \pm 5 \%$ and $95 \pm 4 \%(n=4)$, respectively, of the "pretetanus" baseline values.

Some rats were injected with bicuculline in the lateral ventricle. In these animals, a 13-mm-long, 23 gauge outer cannula was stereotaxically lowered into the right lateral ventricle to a depth of $3.1 \mathrm{~mm}$ from the skull surface and fixed to two skull anchor screws via dental cement. A 14-mm-long, 31 gauge inner cannula was placed through the fixed outer cannula at the time of microinjection; $10-15 \mu \mathrm{g}$ (injection volumes, $0.75-3 \mu 1)$ of either (+)-bicuculline or (-)-bicuculline methiodide dissolved in saline was microinjected into the right cerebral ventricle uver a period of $1 \mathrm{~min}$. Then, the inner cannula was removed after $2 \mathrm{~min}$ more. In some rats (controls), laminar profiles were recorded before and 80-90 min after bicuculline (without tetanization). In the experimental rats, laminar profiles were obtained before and after bicuculline injection and 40-60 min after tetanization (which was delivered 20-30 min after bicuculline). CSD analysis was estimated as described above.

At the end of each experiment, the stimulating electrode positions were marked by lesion with a DC current of $0.5 \mathrm{~mA}$ for $1-10 \mathrm{sec}$. The recording micropipette was placed at the depth of the maximal positive field potential (i.e., presumed stratum pyramidale) and a 5-10 $\mu \mathrm{A}$ anodal current (cerebellar reference screw serving as cathode) was passed for 10-15 min to eject dye from the recording pipette. All animals were perfused with saline and $4 \%$ formaldehyde, and the fixed, excised brains were sliced coronally (40- $\mu$ m-thick sections) and stained with thionin for histological inspection.

\footnotetext{
Figure 1. A, Schematic stimulus and recording electrode positions: frontal sections (from Paxinos and Watson, 1986) at 2.1 and $3.5 \mathrm{~mm}$ posterior to bregma. The tips of the stimulus electrodes were located in stratum oriens and stratum pyramidale of the LCA1 and in the CA3 regions. The recording electrode track was in right $\mathrm{CA} 1$ at P3.5 as indicated. $B$, Stimulus location (arrow) at CA1 stratum oriens for rat in Figures 3 and 4 . $C$, Stimulus location (arrow) at the middle of a lesion for CAl radiatum/moleculare stimulation for rat in Figures 5 and $6 . D$, Stimulus location (arrow) at $\mathrm{CA} 3$ for rat in Figures 7 and 8.
} 
Figure 2. AEP and CSD profiles in CA1 of a control rat, at the peak of the response ( $14 \mathrm{msec}$ latency) evoked by contralateral CA3 stimulation. The "tetanus" was 88 pulses applied at 0.1 $\mathrm{Hz}$ instead of the usual primed bursts. $A$, AEP profiles before (pretet) and after (post-tet) the "tetanus," done $80 \mathrm{~min}$ apart, were similar. $B, C S D$ profiles before and after the control "tetanus" were also similar.
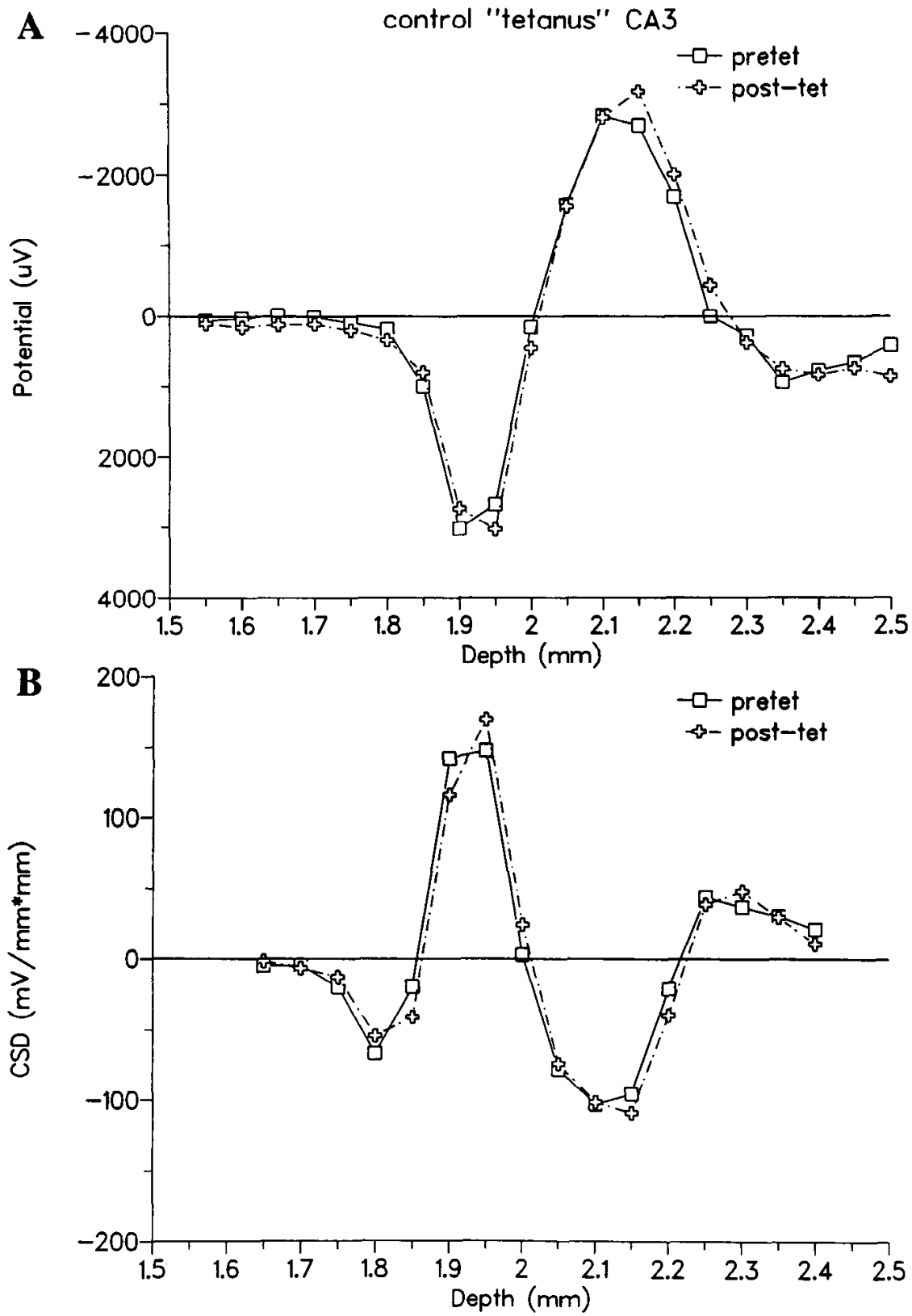

\section{Results}

\section{LCA1 stratum oriens stimulation}

The stimulus threshold for evoking a visually detectable response at the contralateral CAl stratum pyramidale was $110 \pm$ $8.9 \mu \mathrm{A}$ (mean $\pm \mathrm{SEM}, n=8$ ). Following stimulation of the contralateral CA1 stratum oriens (Fig. $1 B$ ), a small negative field potential was found at stratum oriens and a large negative potential at stratum radiatum of CA1, surrounding a high-amplitude positive potential near stratum pyramidale (Fig. $3 A, B$ ). CSD analysis revealed a large and broad sink at the apical dendrites and a small and narrow one at the basal dendrites (Fig. $3 C, 4 A$ ). A major source was found in stratum pyramidale, and a minor one in stratum lacunosum/moleculare. The peak magnitude of the basal dendritic sink was equal to or sometimes larger than that of the apical dendritic one (Fig. $4 A$ ), though the ratio of the total sink (area of the sink) at the apical dendrites to that at the basal dendrites (the apical-to-basal dendritic sink ratio) was $2.07 \pm 0.4(n=8)$.

Tetanization was applied to the LCA1 stratum oriens in eight rats. At $20 \mathrm{~min}$ after the tetanus, the positive AEP peak (population EPSP) at the right CAl cell layer was enhanced to 160 $\pm 20 \%(n=6)$ of the baseline. Immediately after the tetanus, a population spike (not present before the tetanus) was evoked at $2 \times$ threshold stimulus intensity in all rats. The evoked field response at the basal dendrites and cell layer was often potentiated (solid arrow, Fig. 3). However, an increase of the negative field potential at the apical dendrites was rarely seen; the latter was actually decreased in the example shown (open arrow, Fig. 3). The basal dendritic potentiation was confirmed by CSD analysis as a significant increase of the basal dendritic sink, while the apical dendritic sink was relatively unchanged (Fig. $4 B$ com- 
CA1 Stratum Oriens Stimulus
A. AEP Profiles

\section{B. Pretetanus Potential}
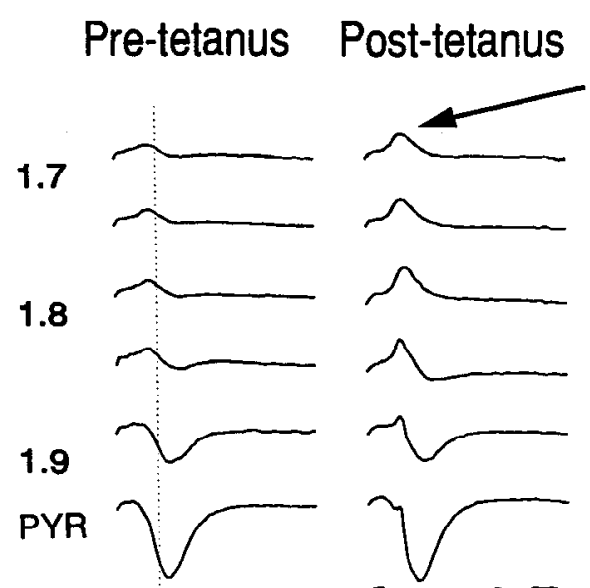

2.0
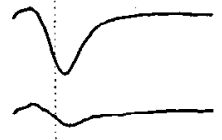

2.1
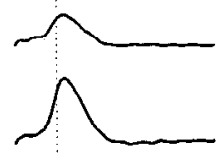

2.2
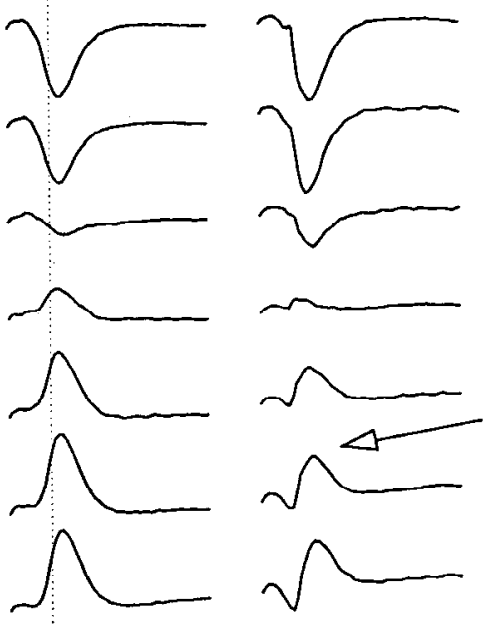

2.4
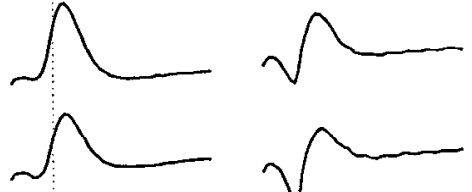

2.3
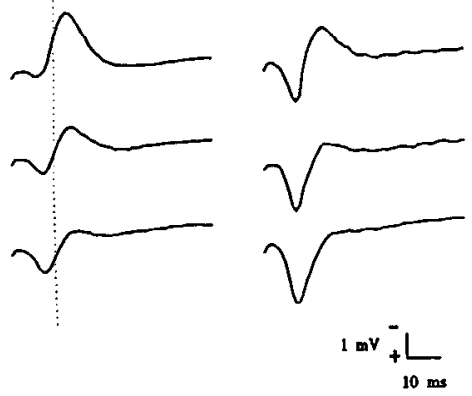

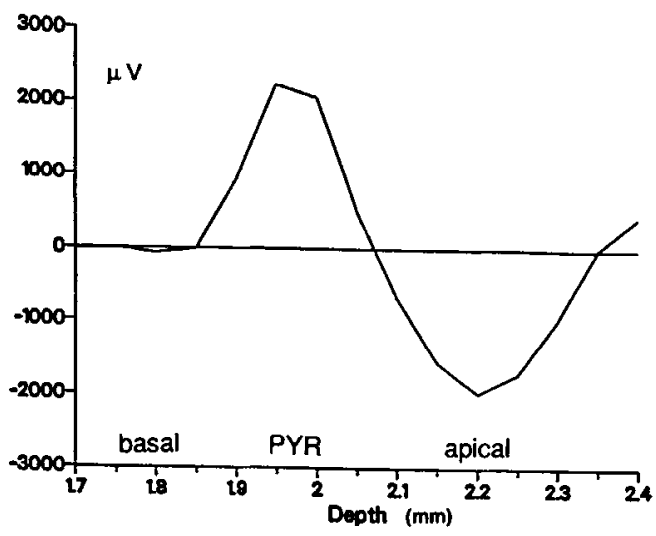

\section{Pretetanus CSD}

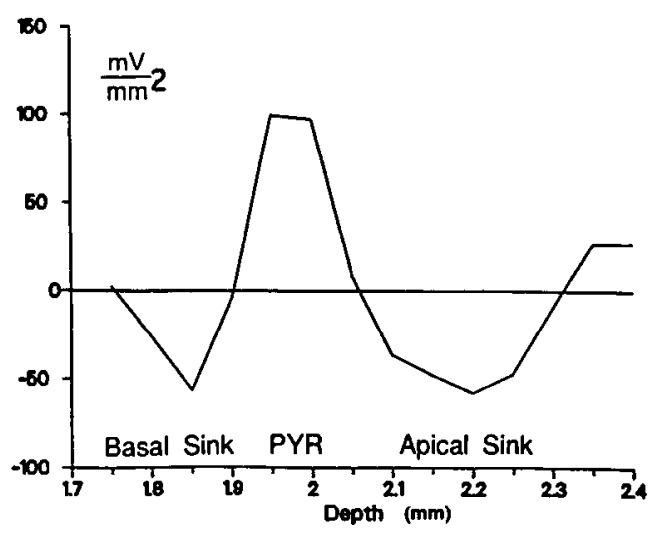

Figure 3. A, Typical AEP profile recorded in CAl at $50 \mu \mathrm{m}$ intervals following stimulus of contralateral $\mathrm{CA} 1$ stratum oriens; AEP sweep was displayed only after the shock artifact. Numbers at left are approximate depths from the neocortical pial surface in millimeters; the exact position of the CAI cell layer was labeled by dye injected at $1.95 \mathrm{~mm}$. After tetanization of the same site (post-tetanus), the surface-negative potential (solid arrow) increased but the deep negative potential (open arrow) decreased. $B$, Field potential map (in $\mu \mathrm{V}$ ) at $14 \mathrm{msec}$ latency (indicated by dotted line in $A$ ) indicates a large negative potential at the apical dendrites and a very small one at the basal dendrites. $C$, CSD profile (in $\mathrm{mV} / \mathrm{mm}^{2}$ ) at $14 \mathrm{msec}$ clearly reveals sinks in both basal and apical dendritic regions, with a major source at the CAl pyramidal cell layer $(P Y R)$ and a minor source in stratum lacunosum/moleculare. $P Y R$ refers to the pyramidal cell layer in this and subsequent figures. pared to Fig. $4 A$ ). Across rats, the peak integrated basal sink was potentiated to $157 \pm 10 \%(n=8)$ of the baseline, whereas the change in the peak integrated apical dendritic sink was 107 $\pm 6 \%$ in the same eight rats (Table 1). This differential potentiation resulted in a significant decrease of the apical-to-basal sink ratio to $1.52 \pm 0.2(n=8$; Table 1$)$. The small (if any) population spike during posttetanus mapping was not large enough to change the CSD profile generated by synaptic currents. However, in order to emphasize the early (presumably monosynaptic) currents without the complication of spiking, CSDs at $2 \mathrm{msec}$ after response onset were integrated at the basal and apical dendritic layers. The amount of potentiation at each dendritic zone at $2 \mathrm{msec}$ from onset was comparable to its respective value at the peak of each sink (Table 1). At $2 \mathrm{msec}$ after onset and at the time of the peak response, the potentiation at the basal dendrites was larger than that at the apical dendrites $(P<0.05$, Wilcoxon).

\section{LCA1 stratum radiatum stimulation}

The threshold for CAl stratum radiatum stimulation was 72.1 $\pm 6.0 \mu \mathrm{A}(n=6)$. The AEP profile revealed an apparent dipole field with a deep-negative field and a surfacc- (and ccll laycr-) positive field (Fig. 5). In contrast to the LCA1 stratum oriens stimulus, a negative potential was not prominent at the alvear surface. As would be expected from the AEP laminar profile, CSD profiles showed a large current sink at the apical dendrites, accompanied by a large source at the cell layer (Fig. $6 A$ ), and a small source at stratum moleculare (not shown in Fig. 6). In addition, CSD analysis also revealed a small current sink at the basal dendrites. The magnitude of the apical dendritic sink was typically larger than the basal dendritic sink (Fig. 6A), giving an apical-to-basal dendritic sink ratio of $2.76 \pm 0.4$ (Table 1).

Tetanization was applied to the LCAl stratum radiatum in six rats. The peak of the positive AEP at the CAl cell layer was 


\section{CA1 Stratum Oriens Stimulus}

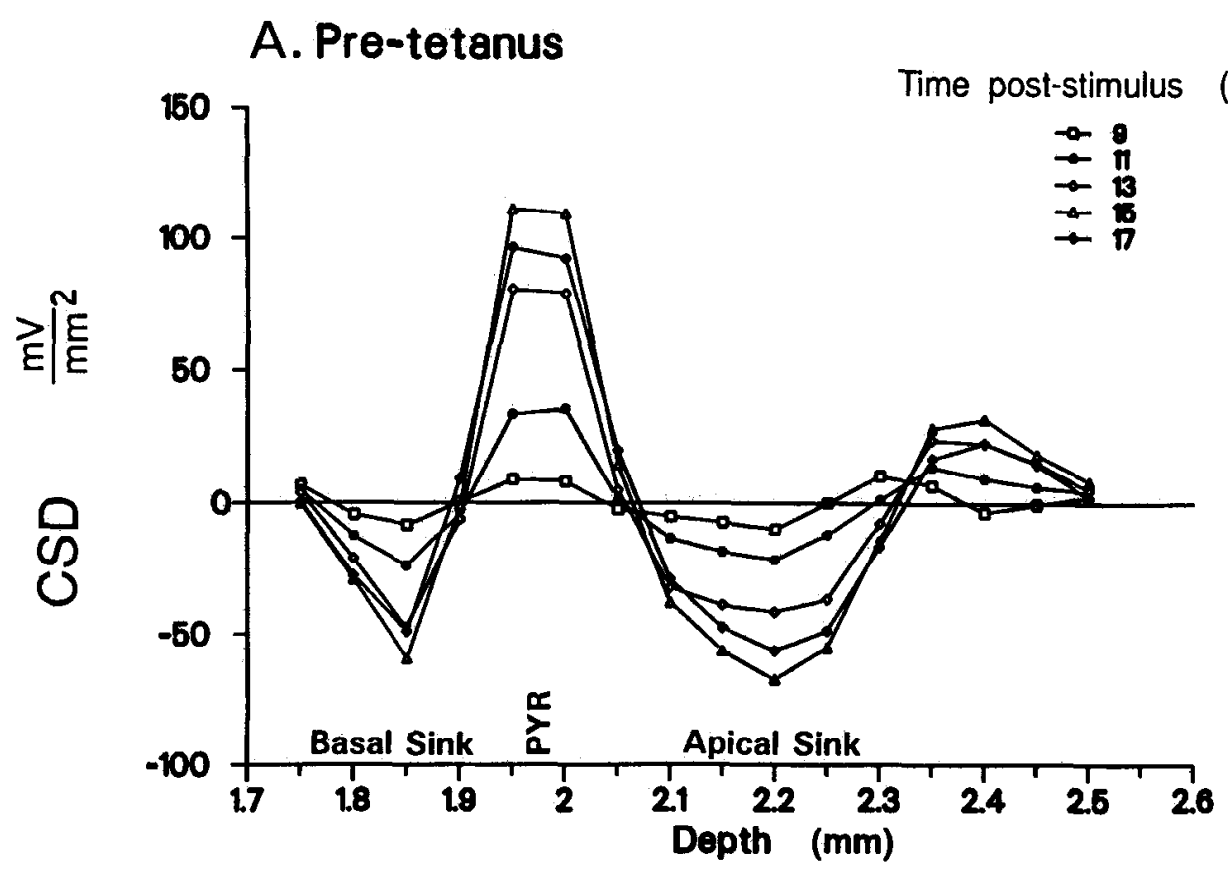

(ms)

Figure 4. CSD profiles along a single vertical track through right $\mathrm{CAl}$ at 9 , $11,13,15$, and $17 \mathrm{msec}$ latency following a test stimulus to CA1 stratum oriens $(A)$. Before tetanus, the basal dendritic and apical dendritic sink and corresponding strata pyramidale and moleculare sources all peaked at 15 msec. $B, 35-50$ min after tetanus, the source sinks still peaked at about 15 msec latency. The basal dendritic sink was potentiated, together with the corresponding pyramidal $(P Y R)$ cell layer source, while the total apical dendritic sink remained relatively unchanged.

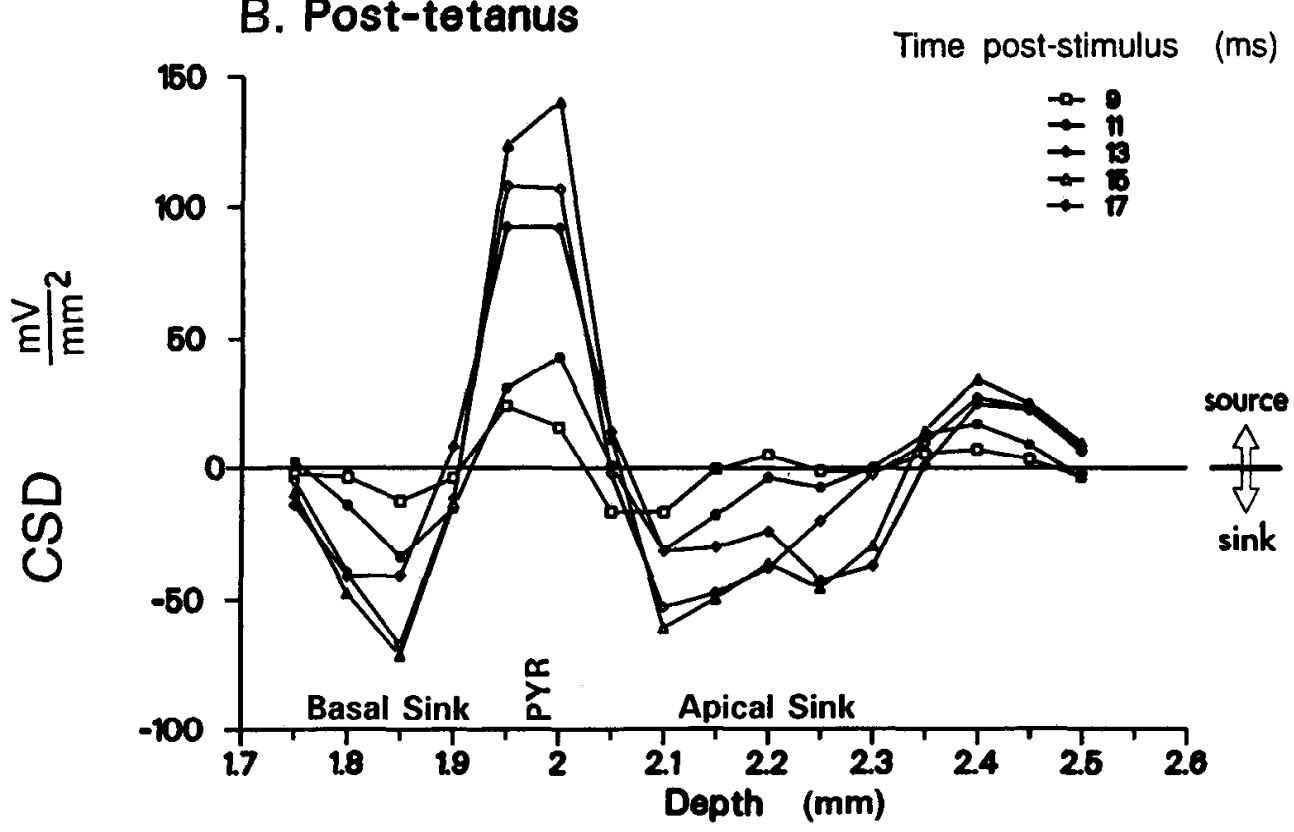

observed to increase to $122 \pm 11 \%(n=5)$ of the baseline at $20 \mathrm{~min}$ after tetanization. However, by the time of AEP mapping at 30-60 min posttetanus, depression rather than potentiation of the field potential at the apical dendrites was often observed (Fig. 5). The CSDs indicated little posttetanic change in the basal dendritic sink at any latencies (Table 1). Posttetanic change of the apical dendritic sink was found to be significantly depressed only at the peak and not at the rise ( $2 \mathrm{msec}$ from onset) of the sink (Table 1). At the peak, the apical dendritic sink was depressed to $81 \pm 7 \%(n=6)$ of the baseline value, while the basal dendritic sink was relatively unchanged at $94 \pm 15 \%(n=6$; Table 1). The apical-to-basal sink ratio was slightly but not significantly reduced after the tetanus to $2.49 \pm 0.5$ (Table 1).

\section{LCA3 stimulation}

The stimulus threshold at CA3 was $69.1 \pm 6.4 \mu \mathrm{A}(n=11)$, lowest among the three stimulus sites. The AEP profile (Fig. 7) was similar to that following CAl stratum oriens stimulation; that is, negative responses were observed at the alvear surface and apical dendrites, flanking a cell layer-positive response. Activation of both the basal and apical dendrites was confirmed by sinks in strata oriens and radiatum (Fig. $8 \mathrm{~A}$ ). The apical-tobasal dendritic sink ratio was $2.97 \pm 0.7$ (Table 1). LCA3 stimulation, however, evoked responses that were faster than those evoked by LCA1 stratum oriens stimulation.

CA3 was tetanized in 11 rats. The peak positive response at 
Table 1. Integrated basal dendritic and apical dendritic sink size (in $\mathrm{mV} / \mathrm{mm}^{2}$ ), apical-to-basal dendritic sink ratio (A:B), and percentage change of sink after a homosynaptic tetanus

\begin{tabular}{|c|c|c|c|c|}
\hline Stimulus site/condition & $\begin{array}{l}\text { CA1 } \\
\text { stratum oriens } \\
(n=8)\end{array}$ & $\begin{array}{l}\text { CA1 stratum } \\
\text { radiatum } \\
(n=6)\end{array}$ & $\begin{array}{l}\text { CA3 } \\
(n=11)\end{array}$ & $\begin{array}{l}\text { CA1 radiatum } \\
\text { Bicuculline } \\
(n=6)\end{array}$ \\
\hline \multicolumn{5}{|l|}{ Pretetanus peak sink size } \\
\hline Basal sink $\left(\mathrm{mV} / \mathrm{mm}^{2}\right)$ & $89 \pm 15$ & $108 \pm 33$ & $70 \pm 9$ & $40 \pm 8$ \\
\hline Apical sink $\left(\mathrm{mV} / \mathrm{mm}^{2}\right)$ & $164 \pm 22$ & $253 \pm 49$ & $163 \pm 22$ & $178 \pm 33$ \\
\hline $\mathrm{A}: \mathrm{B}$ & $2.07 \pm 0.4$ & $2.76 \pm 0.4$ & $2.97 \pm 0.7$ & $4.76 \pm 0.4$ \\
\hline \multicolumn{5}{|l|}{ Posttetanus peak sink size } \\
\hline Basal sink $\left(\mathrm{mV} / \mathrm{mm}^{2}\right)$ & $134 \pm 18$ & $100 \pm 24$ & $86 \pm 10$ & $57 \pm 7$ \\
\hline Apical sink $\left(\mathrm{mV} / \mathrm{mm}^{2}\right)$ & $187 \pm 27$ & $212 \pm 48$ & $179 \pm 27$ & $220 \pm 30$ \\
\hline $\mathrm{A}: \mathrm{B}$ & $1.52 \pm 0.2^{*}$ & $2.49 \pm 0.5$ & $2.54 \pm 0.5$ & $3.86 \pm 0.3^{*}$ \\
\hline \multicolumn{5}{|c|}{ Posttetanus percentage change at peak of sink } \\
\hline Basal sink (\%) & $157 \pm 10^{*} \dagger$ & $94 \pm 15$ & $130 \pm 9^{*}$ & $168 \pm 19 * \dagger$ \\
\hline Apical sink (\%) & $107 \pm 6$ & $81 \pm 7^{*}$ & $109 \pm 10$ & $123 \pm 8^{*}$ \\
\hline \multicolumn{5}{|c|}{ Posttetanus percentage change at $2 \mathrm{msec}$ after sink onset } \\
\hline Basal sink (\%) & $167 \pm 18^{*} \dagger$ & $121 \pm 19$ & $153 \pm 18^{* *}$ & $169 \pm 35^{*} \dagger$ \\
\hline Apical sink (\%) & $119 \pm 15$ & $115 \pm 32$ & $136 \pm 21$ & $120 \pm 7^{*}$ \\
\hline
\end{tabular}

${ }^{*} p<0.05,{ }^{* *} p<0.01$, Pre- versus posttetanus change in sink size or A:B ratio, Wilcoxon.

$\dagger p<0.05$, basal dendritic larger than apical dendritic sink change, matched Wilcoxon.

the CAl cell layer was increased to $152 \pm 9 \%(n=8)$ of the baseline at $20 \mathrm{~min}$ after the tetanus. Immediately after the tetanus, a population spike was observed at $2 \times$ threshold stimulus intensity in seven of eight rats (but it was not observed in any of the rats before tetanus). In the example shown, tetanization resulted in a potentiation of the field potential at the basal dendrites and, to a lesser degree, that at the apical dendrites (Fig. 7). CSD analysis confirmed that the potentiation of the peak integrated sink at the basal and apical dendrites for the particular example was $178 \%$ and $128 \%$, respectively (Fig. 8). As a group, the peak basal dendritic sink was found to be potentiated to 130 $\pm 9 \%$ while the peak apical dendritic sink was relatively unchanged at $109 \pm 10 \%(n=11)$ and the apical-to-basal sink ratio decreased slightly (Table 1). Analysis of basal and apical sinks at $2 \mathrm{msec}$ from response onset gave similar values (Table 1). There was no significant correlation between the magnitude of potentiation of the apical dendritic sink and the stimulus threshold or between potentiation and the apical-to-basal dendritic sink ratio.

\section{Latency and conduction velocity}

In control animals, the onset latency was shortest with contralateral CA3 stimulus, at $6.4 \pm 0.4 \mathrm{msec}(n=10)$ while that for a contralateral CA1 stimulus, at either stratum oriens or radiatum, was $8.2 \pm 0.4 \mathrm{msec}(n=8, n=6$, respectively). Assuming a $0.5 \mathrm{msec}$ fixed delay in stimulation and synaptic delay, and that the activated commissural fibers projected in a straight line through the ventral hippocampal commissure (at P1.3), the onset latencies translated to a conduction velocity of about $0.9 \mathrm{~m} /$ sec for each stimulus site. For any stimulation, the response at the basal dendrites apparently rose more quickly than that at the apical dendrites. At $2 \mathrm{msec}$ following response onset, the basal dendritic sink typically reached half-maximal value while the apical dendritic sink reached less than $30 \%$ of its peak value. In about half of the rats, the onset of the basal dendritic sink appeared to be earlier than the apical dendritic sink, but as a group, the difference was not significant.

\section{CA1 Stratum Radiatum Stimulus AEP Profiles}

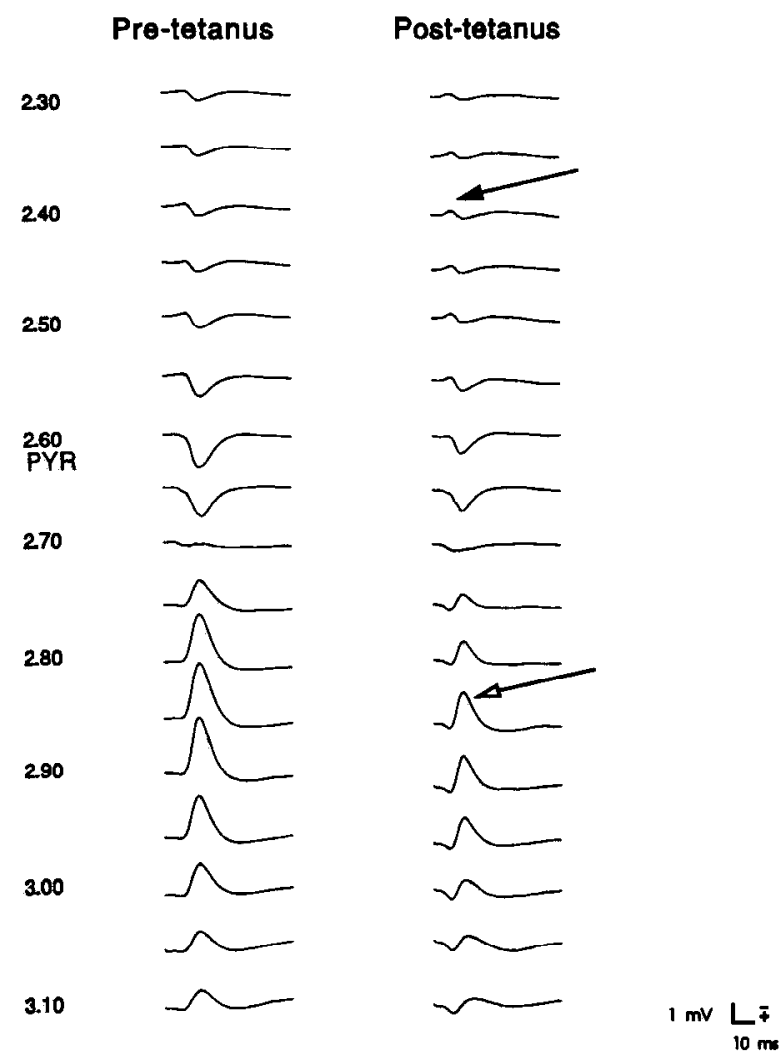

Figure 5. Responses recorded along a single track in right $\mathrm{CA1}$ following a test stimulus applied to the contralateral CA1 stratum radiatum site: AEP laminar profiles recorded before and after tetanization, pyramidal cell layer was shown by dye injection. Note the increased prominence of the surface-negative response after the tetanus (solid arrow). Following tetanization, the negative field potential at the apical dendrites was decreased (open arrow) as well as the positive potential at the cell layer. 


\section{CA1 Stratum Radiatum Stimulus}

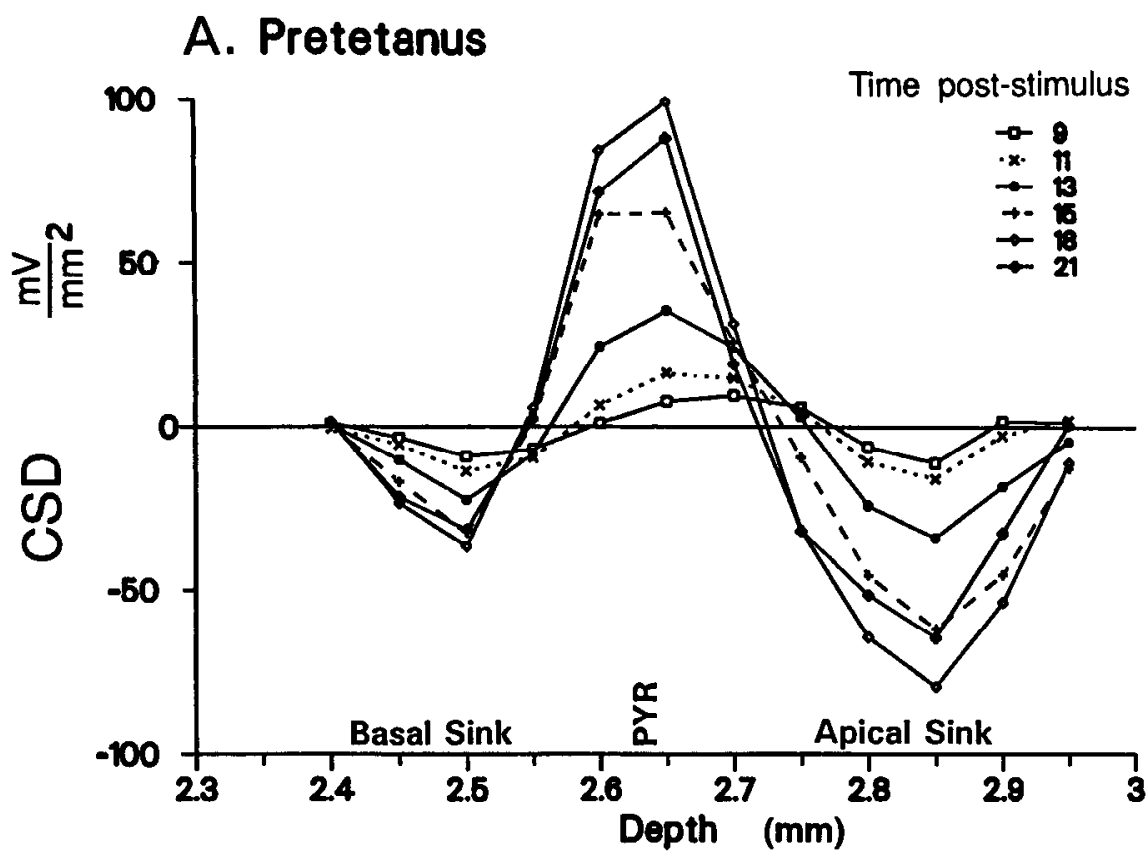

(ms)

Figure 6. CSD profile in right $\mathrm{CA} 1$ at $9,11,13,15,18$, and $21 \mathrm{msec}$ latency following a test stimulus to LCA1 stratum radiatum. $A$, Before tetanization of the same pathway, there was a large sink at the apical dendrites and a smaller one at the basal dendrites, surrounding a cell body source. $B$, At $40-60$ min after tctanization, the apical dendritic sink and the cell body source were depressed, but the basal dendritic sink was relatively unchanged.

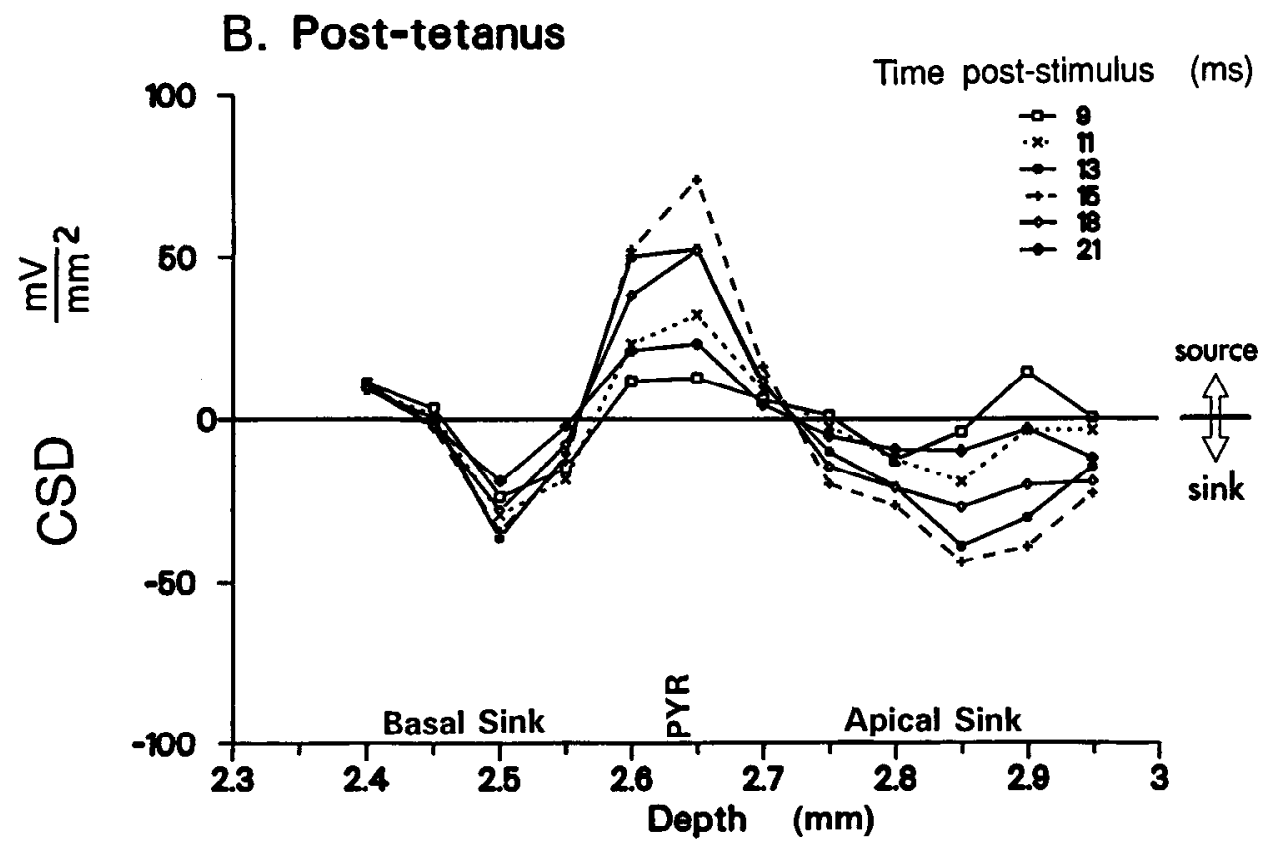

\section{Heterosynaptic responses}

Paired pulses applied to two separate sites (among CAl stratum oriens, $\mathrm{CA} 1$ stratum radiatum, and CA3) at low intensity and 30-50 msec interpulse intervals did not result in "heterosynaptic" facilitation, while paired pulses delivered to the same site ("homosynaptic") revealed facilitation (not shown). This suggests that a low-intensity stimulus at each site was mainly activating a different set of synapses than stimulus at a different site.

Following tetanization of the CA3 pathway, peak responses to test pulses applied to $\mathrm{CA} 1$ stratum radiatum were depressed in five of six rats $(74 \pm 13 \%, n=6$, of the integrated apical sink

before tetanus). However, at $2 \mathrm{msec}$ after response onset, no significant change in heterosynaptically evoked sink size was found.

\section{Apical dendritic LTP following bicuculline injection}

It was hypothesized that the lack of LTP at the apical dendrites may result from tonic or evoked inhibition (see Discussion). In order to test this hypothesis, $\mathrm{GABA}_{\mathrm{A}}$-mediated inhibition was blocked by an intraventricular injection of bicuculline, before the delivery of the primed burst. Only the $\mathrm{CAl}$ stratum radiatum was tetanized, since this site resulted in a consistent depression of the peak apical dendritic sink.

The stimulus threshold for this group was $67.8 \pm 8.7 \mu \mathrm{A}$ ( $n$ 
$=6$ ), similar to the previous group using CA1 stratum radiatum as a tetanus site. Following the injection of bicuculline into the lateral ventricle, physiological effects were observed within a couple of minutes. The effects included an increased breathing rate, and an increase in the late ( $20-40 \mathrm{msec}$ latency) evoked responses. Less consistently observed was an enhancement of the EPSP at early latency, which was occasionally accompanied by a population spike. However, by $80-90$ min after bicuculline (no tetanus was given), little change of the AEP laminar profiles was observed and the integrated sinks at the basal and apical dendrites were $99 \pm 8 \%$ and $94 \pm 3 \%(n-5)$, respectively, of the baseline values. If a tetanus was delivered in the presence of bicuculline, the field response at both basal and apical dendritic regions were potentiated. CSD profiles at $40-60$ min posttetanus revealed potentiation of both the basal and the apical dendritic sinks, at $2 \mathrm{msec}$ from onset or at the peak (Fig. 9). Across six rats, the peak basal and apical dendritic sinks showed significant potentiation at $168 \pm 19 \%$ and $123 \pm 8 \%$, respectively, with similar potentiation values at $2 \mathrm{msec}$ from response onset (Table 1).

\section{High-frequency tetanization}

A 1 sec train of pulses at $200 \mathrm{~Hz}$ and $400-600 \mu \mathrm{A}(0.2 \mathrm{msec}$ duration) was delivered to the contralateral CA3 in five rats. In all five rats, the change of the basal dendritic sink was greater than that of the apical dendritic sink. The basal dendritic sink was increased to $113 \pm 9 \%(n=5)$ of the baseline, somewhat smaller than that following a primed burst, while the apical dendritic sink change was relatively unchanged at $102+7 \%$ of the baseline.

\section{Discussion}

\section{Validity of CSD analysis}

CSD analysis has been applied to the study of hippocampal LTP. Melchers et al. (1986) concluded that sink (excitation) following perforant path stimulation increased more at the proximal than the distal dendrites of the dentate granule cells. Taube and Schwartzkroin (1988) observed early sinks at the CA1 radiatum/pyramidale border and late sinks at the proximal basal dendrites following stratum radiatum stimulation in the in vitro slice. These in vitro sinks were probably related to synchronous (population) spiking, which was of low threshold and prominent in the slice in vitro but not in vivo. Except for the few minutes immediately posttetanus, population spikes were not prominent and they did not appear in the laminar profiles (evoked at $2 \times$ response threshold) of this study.

As far as we know, no previous study has addressed the quantitative changes of the synaptic responses at the basal versus the apical dendritic regions of CA1. The use of the CSD is essential in this study, since it separates the basal and the apical dendritic excitatory currents. The field potential is a sum of the local and distant currents flowing through a volume-conducting medium. Similarly, the intracellular potential recorded by a single microelectrode reflects the sum of basal and apical excitatory currents electrotonically conducted through the somatodendritic processes. Thus, other than using voltage-sensitive dyes (cf. Grinvald et al., 1988), CSD is the best technique that can separate the basal and apical dendritic excitation.

The excitatory activation of CAl at or near the synaptic site was typically observed as a negative deflection of the extracellular field potential. However, the lack of a negative potential at the synapse by no means indicates an absence of local synaptic

\section{CA3 Stimulus AEP Profiles}

Pre-tetanus

1.60

1.70

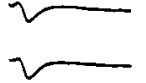

1.80
PYR

1.90

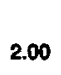

2.00

2.10

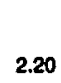

2.20

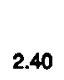

2.40

2.50
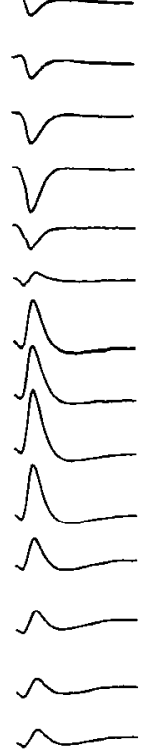

$\sim$

$\sim$

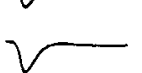

Post-tetanus

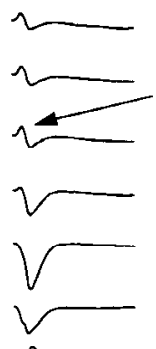

r.m
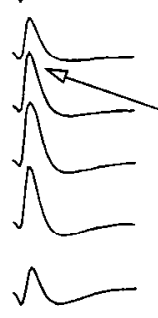

$\sqrt{ }$

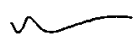

$\sim$

$\sim$

$\sim$

Figure 7. Responses recorded in right CA1 following a test stimulus applied to the contralateral LCA3: AEP profiles recorded before and after tetanization of the same site. Onset latencies were shorter than after LCA I stimuli (Figs. 3, 5). In this example, both the surface-negative (solid arrow, basal dendritic) and the deep (open arrow, apical dendritic) negative potentials were enhanced following tetanization.

activation. Following contralateral CA1 stratum radiatum stimulus, a surface-negative potential was not usually observed at the basal dendrites since the field was dominated by the major source and sink pair at the cell layer and apical dendrites, respectively (Figs. 5, 7). However, CSD analysis clearly revealed a basal dendritic sink, and this sink became more prominent after tetanization, often giving rise to a clear surface-negative field potential after a tetanus (Figs. 5, 7). In conclusion, the field potential, especially at sites distal to the largest sink or source, may be dominated by distal sources and sinks through volumeconducted currents. Thus, interpretation of the polarity and amplitude (or its change after a tetanus) has to be made with caution.

\section{Commissural activation of basal and apical dendrites of $C A 1$}

Stimulation of the CA1 resulted in excitation at both the basal and apical dendrites of the contralateral $\mathrm{CA} 1$, being strongest at the point homotopic to stimulation (Andersen, 1960). Contralateral CA1 stimulation presumably antidromically fired CA3 cells bilaterally via the associational/commissural (CA3 to CA1) pathways (Swanson et al., 1978; Buzsaki and Eidelberg, 1982a). In this study, diffcrent CAl stimulations served to activate different sets of afferents to the contralateral CA1. It may be inferred that stimulation of the contralateral CA 1 stratum oriens activated axons (or CA3 cells) that, as a population, projected 


\section{CA3 Stimulus}
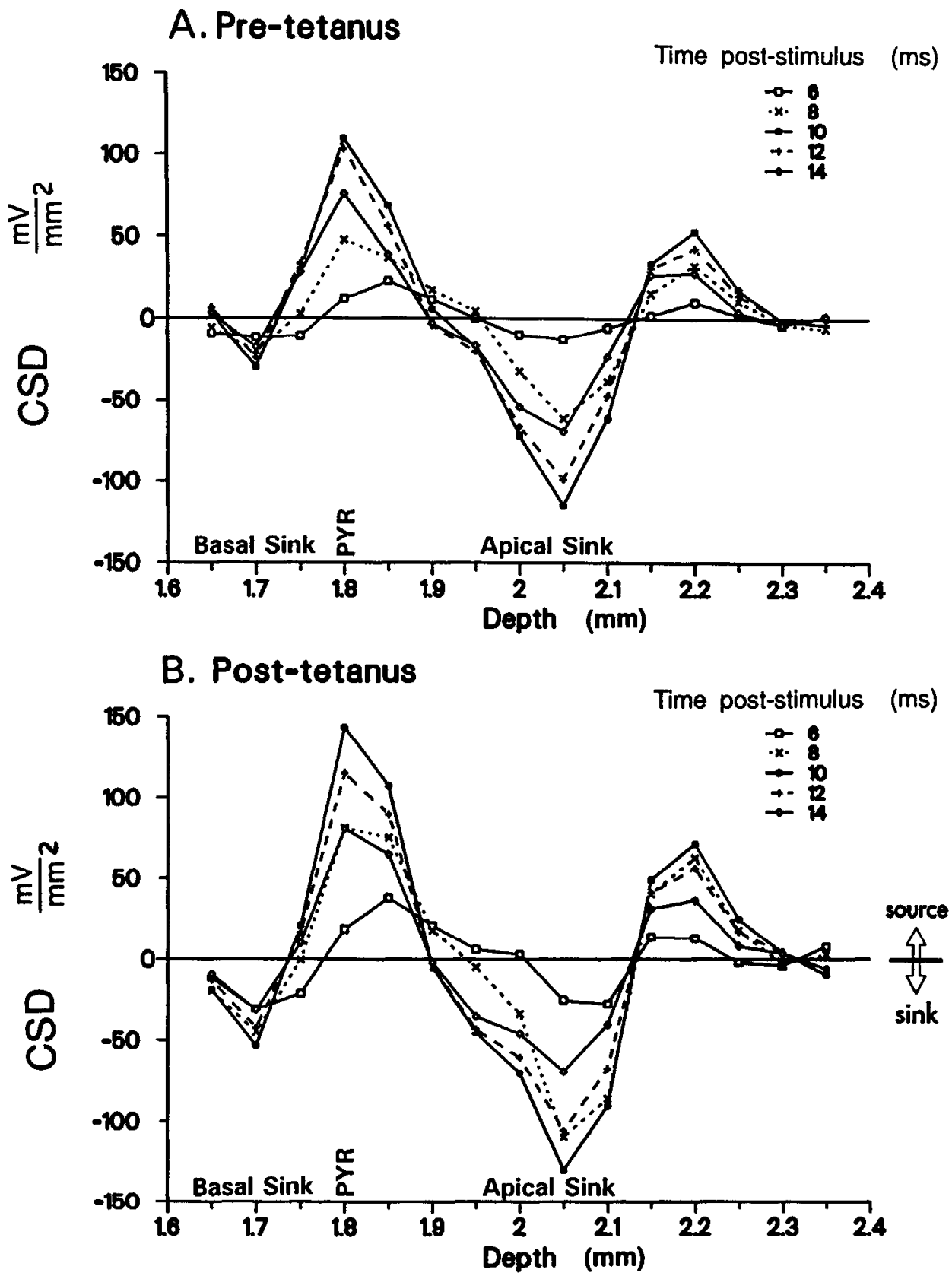

Figure 8. A, CSD profile in RCA1 at $6,8,10,12$, and $14 \mathrm{msec}$ latency following a test stimulus to contralateral CA3; sinks are seen at both the basal and apical dendrites. $B, C S D$ profile following tetanization of same site indicates potentiation of the basal dendritic and, to a lesser degree, the apical dendritic sink.

about equally to stratum oriens and stratum radiatum of CA1. However, stimulation of contralateral CA1 stratum radiatum activated axons (or CA3 cells) that projected largely to CAl stratum radiatum (apical dendrites). Direct stimulation of the contralateral CA3 excited cells of both types, those that projected equally to both the basal and the apical dendrites of CAl and those that projected largely to the apical dendrites. Anatomical studies indicate that interhilar CA3 and CA4 projected more to the stratum radiatum than stratum oriens of the contralateral CA1 (Fig. 5 of Gottlieb and Cowan, 1973; Laurberg, 1979), while other parts of CA3 projected more to the stratum oriens than stratum radiatum of the contralateral CA1 (Swanson et al., 1978). As would be expected, direct stimulation of CA3 cells was more effective (lower threshold) than stimulation of contralateral CA1 in exciting commissural afferents to CA1.

Andersen et al. (1978) reported that the afferent fibers in stratum oriens and radiatum of CA1 in the hippocampal slice had a conduction velocity of $0.3 \mathrm{~m} / \mathrm{sec}$. However, whether these were commissural fibers was not known. Similarly, the conduction velocity of the fastest fimbria fibers was measured at $7.5 \mathrm{~m} / \mathrm{sec}$ in the rat (Andersen, 1960) but this did not consider conduction along the smaller axonal branches from CA3 to CA1. We estimated that the fastest commissural fibers (from contralateral CA3 or CA1) projecting to CA1 conducted at $0.9 \mathrm{~m} / \mathrm{sec}$. 


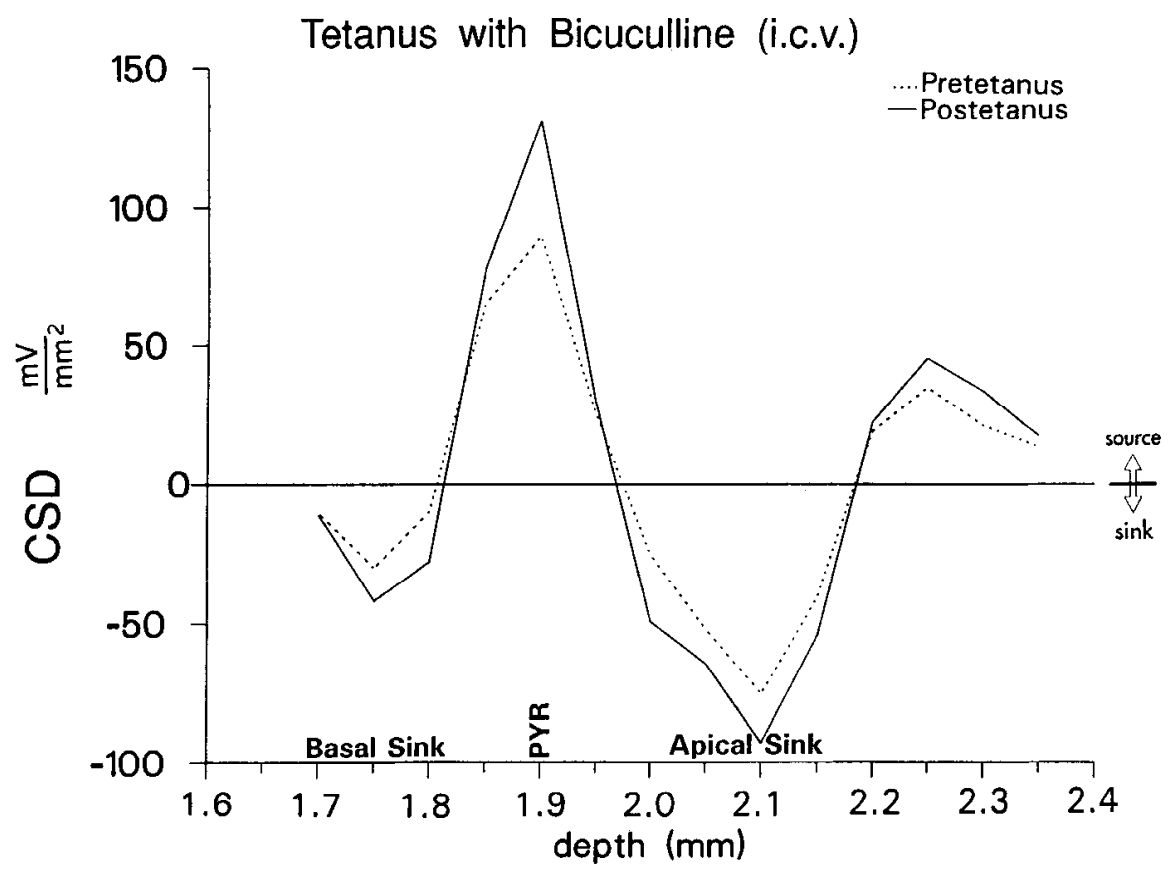

Figure 9. Peak CSD profiles following an LCA1 stratum radiatum stimulus before and after tetanus of the same pathway in the presence of intraventricular bicuculline in a representative rat. Potentiation of both the basal dendritic and the apical dendritic current sinks was found.

\section{Differential potentiation of basal and apical dendritic sinks}

A differential propensity toward synaptic plasticity was observed at the basal and apical dendrites of CA1 pyramidal cells. When the basal dendrites were a major site of excitation, following a contralateral CA1 stratum oriens or CA3 stimulation, LTP was consistently observed at the basal dendritic synapse. When the apical dendritic synapse was the major site of excitation, following a contralateral CAl stratum radiatum stimulation, little LTP was observed and, in fact, depression of the apical dendritic response was sometimes observed. However, in the situation where both apical and basal dendrites were strongly activated, as evoked by a contralateral CA3 stimulation, many experiments (6 of 11) revealed an apical dendritic LTP.

Potentiation of the EPSP at the apical and basal dendrites (evoked by stratum radiatum and stratum oriens stimulation, respectively) appeared to be achieved with equal ease in the hippocampal slice in vitro (Andersen et al., 1980; Sastry et al., 1986; Diamond et al., 1988). However, in these and other studies, the extracellular medium was often manipulated (e.g., by increase in $\mathrm{K}^{+}$and $\mathrm{Ca}^{2+}$ ) to facilitate LTP and quantitative measures of the success rate of LTP at each dendritic site have not been reported. The in vitro hippocampal slice was more excitable than the hippocampus in situ. The stimulus threshold of the afferent evoked CAl population spike in the transverse slice was typically $<1.5 \times$ the population EPSP threshold in vitro (cf. Zhao and Leung, 1991), but $>2 \times$ the EPSP threshold intensity in the anesthetized rat or the freely moving rat (Leung, 1980). The increased excitability probably resulted from severing the spatially extensive collaterals of the inhibitory interneurons, thus reducing the tonic or evoked inhibition (Schwartzkroin, 1981). On account of the inherent differences between in vivo (in situ) and in vitro preparations, the success rate for LTP is not expected to be the same in the two preparations.

LTP has been reported for the hippocampal CAl in vivo (Buz- saki, 1980; Bliss et al., 1983; Diamond et al., 1988), but few studies distinguished between basal dendritic versus apical dendritic excitation or LTP. Bliss et al. (1983) showed examples of an enhancement of a negative field potential at the CA1 apical dendrites following CA3 tetanization in urethane-anesthetized rats. However, the latter rats had an unilateral kainic acid lesion, which resulted in reduced inhibition in CAl among other abnormalities (Schwartzkroin, 1986). After a theta pattern burst tetanus delivered to CA3 in behaving rats, Staubli and Lynch (1987) reported a $30 \%$ increase of the negative response at the CA1 stratum radiatum. The latter and other reports of potentiation at the apical dendritic synapse following ipsilateral stimulation (cf. Hesse and Teyler, 1976) were not at odds with the results here. Our main result was that the apical dendritic LTP was less robust than the basal dendritic LTP. Though we did not find it in this study, apical dendritic LTP was apparently more readily elicited in the freely moving rat by a high-frequency (50-200 Hz) tetanus that typically evoked an afterdischarge (Buzsaki, 1980; Leung and Shen, 1992; afterdischarges were also observed by Staubli and Lynch, 1987).

\section{Mechanisms underlying differential LTP capability}

It is possible that the differential propensity for LTP is caused by the difference in the excitatory synapses at the basal and apical dendrites. We are not aware of any overt ultrastructural differences between the excitatory (spine) synapses on the basal and apical dendrites of CA1 pyramidal cells. Several anatomical studies reported a generally heavier commissural projection to stratum oriens than radiatum of CAl (Swanson et al., 1978; Laurberg, 1979; van Groen and Wyss, 1988). However, dense commissural projection to the CAl stratum radiatum has also been reported (Gottlieb and Cowan, 1973; Laurberg, 1979), as confirmed by the major sink in stratum radiatum in this study. Thus, it is not likely that an excitatory (depolarizing) input was lacking at the apical dendrites following commissural stimulation. It is, however, possible that the NMDA receptor at the 
apical dendritic synapse is modulated differently than that at the basal dendritic synapse; for example, glycine may not be present at the former synapse (cf. Young and Fagg, 1990).

An established mechanism for the control of LTP is inhibition, and differential inhibition at the apical and basal dendrites may result in differential propensity for LTP. GABA $A_{\Lambda}$ antagonists decreased the threshold and increased the success rate of LTP (Wigstrom and Gustafsson, 1985; Gustafsson and Wigström, 1988). The suppression of inhibition may enhance the tetanus-induced depolarization sufficiently to activate NMDA receptors (Gustafsson and Wigström, 1988). It is known that commissural stimulation may activate inhibitory interneurons in a feed-forward fashion (Buzsaki and Eidelberg, 1982a; Frotscher et al., 1984; Schwartzkroin and Kunkel, 1985; Kunkel et al., 1988). There may be some difference in the inhibition evoked by afferents coursing in stratum oriens versus those in stratum radiatum. Afferents in the stratum radiatum may excite the lacunosum $/ \mathrm{moleculare}$ interneurons ( $\mathrm{L} / \mathrm{M}$ interneurons) that hyperpolarized the apical dendrites (Lacaille and Schwartzkroin, 1988; Lambert et al., 1991). In contrast, afferents in stratum oriens may excite the alveus/oriens interneurons $(\mathrm{O} / \mathrm{A}$ interneurons; Lacaille et al., 1987), which seemed to hyperpolarize the CAl cells maximally at the pyramidale/oriens border (Lambert et al., 1991). Apical dendritic afferents may be less effective than basal dendritic afferents in eliciting LTP because of the relative robust apical dendritic inhibition during the patterned primed burst tetanus. Perhaps the O/A interneurons did not mediate inhibition directly on the basal dendrites, as opposed to a direct apical dendritic inhibition by $\mathbf{L} / \mathbf{M}$ interneurons. Furthermore, $\mathrm{L} / \mathrm{M}$ interneurons had an intrinsic propensity to spontaneous bursting at the theta frequency (Lacaille et al., 1987; Lacaille and Schwartzkroin, 1988; Fraser and MacVicar, 1991), suggesting that a theta frequency tetanus may maximally activate the $\mathrm{L} / \mathrm{M}$ but not the $\mathrm{O} / \mathrm{A}$ interneurons.

The involvement of inhibitory mechanisms in suppressing apical dendritic LTP was confirmed by the application of a tetanus in the presence of bicuculline, a $\mathrm{GABA}_{\mathrm{A}}$ antagonist. With bicuculline, both the basal and apical dendrites showed significant potentiation following tetanization (about $170 \%$ and $120 \%$, respectively). The larger basal dendritic than apical dendritic LTP may result from a higher concentration of bicuculline at the basal dendrites, which are closer to the lateral ventricle (site of injection), than the apical dendrites. Alternatively, it may be suggested that some differences between basal and apical dendritic LTP remained after bicuculline. Similarly, LTP could be elicited at the commissural to dentate gyrus afferents only after bicuculline infusion (Douglas et al., 1982; Steward et al., 1990).

Davies et al. (1991) reported that theta frequency primed burst was incapable of eliciting LTP in CA1 cells following a high dose of $\mathrm{GABA}_{\mathrm{B}}$ antagonist that presumably blocked the presynaptic $\mathrm{GABA}_{\mathrm{B}}$ receptors. It may be suggested that inhibitory interneurons at the apical dendrites may be subjected to less $\mathrm{GABA}_{\mathrm{B}}$ presynaptic inhibition than the interneurons at the basal dendrites. However, we have no evidence for or against the latter hypothesis.

The possibility of potentiating the basal but not the apical dendritic synapse on the same cell suggests that LTP may be expressed at discrete dendritic locations, even though both synapses are activated. The expression of LTP may be controlled by the local postsynaptic depolarization during the tetanus, as shown by White et al. (1988) for the dentate gyrus. Here, we inferred that the dendritic depolarization is controlled also by the local inhibition.

\section{Depression}

Homosynaptic depression of the peak but not the early rising phase of the apical dendritic sink was observed, often following tetanization of CAl stratum radiatum (Table 1). The mechanism underlying this depression is not known. It is possible that interneurons may be potentiated (Buzsaki and Eidelberg, 1982b; Taube and Schwartzkroin, 1987), and that they mediated a late inhibition, either postsynaptically (shunting EPSP currents) or presynaptically. The heterosynaptic depression of the CA1 radiatum response following CA3 stimulation may be similarly mediated. Whether the depression relates to that following lowfrequency stimulus (Staubli and Lynch, 1990) or that in the visual cortical neurons (Artola et al., 1990) remains to be studied.

\section{Functional significance of differential LTP}

While an experimental stimulus is inherently artificial, it may be argued that similar activation patterns may be produced by physiological activity of particular sets of CA3 cell. A CA3 cell may project, in different proportions, to the apical and basal dendritic layers of CA1 (cf. Tamamaki et al., 1988; Ishizuka et al., 1990). Furthermore, CA3 cells sometimes fired a series of complex spikes (at an instantaneous frequency of 100-200 Hz) that are modulated at the theta frequency (Ranck, 1973; Buzsaki et al., 1983), somewhat similar to the patterned primed burst tetanus.

The differential propensity for LTP at basal and apical dendritic synapse in this study confirmed and extended the results of an earlier study using field potentials in behaving rats (Leung et al., 1992). In addition, we now have preliminary data that in the behaving rat, the apical dendritic LTP, when elicited, was mainly resistant to NMDA antagonist 2-amino-5-phosphonovalerate (APV), while the basal dendritic LTP was blocked by APV (Leung and Shen, 1992, 1993). Basal and apical dendritic responses were also modulated by behavior in different ways (Leung, 1980; Buzsaki et al., 1981). At this point, the functional significance of the differential LTP can only be speculated. On account of its low threshold and relatively transient nature (Leung et al., 1992), basal dendritic potentiation would increase and decrease relatively quickly, while the apical dendritic LTP would occur only after a certain degree of disinhibition, perhaps provided by coactivation of the basal dendritic afferents or other subcortical or entorhinal afferents to CA1.

\section{References}

Abraham WC, Bliss TVP, Goddard GV (1985) Heterosynaptic changes accompany long-term but not short-term potentiation of the perforant path in the anaesthetized rat. J Physiol (Lond) 363:335-349.

Andersen P (1960) Interhippocampal impulses. II. Apical dendritic activation of CAl neurons. Acta Physiol Scand 48:178-208.

Andersen P, Silfvenius H, Sundberg SH, Sveen O, Wigstrom H (1978) Functional characteristics of unmyelinated fibres in the hippocampal cortex. Brain Res 144:11-18.

Andersen P, Sundberg SH, Sveen O, Swann JW, Wigstrom H (1980) Possible mechanisms for long-lasting potentiation of synaptic response in hippocampal slices from guinea pigs. J Physiol (Lond) 320: $463-482$.

Artola A, Bröcher S, Singer W (1990) Different voltage-dependent thresholds for inducing long-term depression and long-term potentiation in slices of rat visual cortex. Nature 347:69-72.

Blackstad TW (1956) Commissural connections of the hippocampal 
region in the rat, with special reference to their mode of termination. J Comp Neurol 105:417-537.

Bliss TVP, Lomo T (1973) Long-lasting potentiation of synaptic transmission in the dentate area of the anaesthetized rabbit following stimulation of the perforant path. J Physiol (Lond) 232:331-356.

Bliss TVP, Lancaster B, Wheal HV (1983) Long-term potentiation in commissural and Schaffer projections to hippocampal CA1 cells: an in vivo study in the rat. J Physiol (Lond) 341:617-626.

Buzsaki G (1980) Long-term potentiation of the commissural pathCA1 pyramidal cell synapse in the hippocampus of the freely moving rat. Neurosci Lett 19:293-296.

Buzsaki G, Eidelberg E (1982a) Convergence of association and commissural pathways on CAl pyramidal cells of the rat hippocampus. Brain Res 237:283-295.

Buzsaki G, Eidelberg E (1982b) Direct afferent excitation and longterm potentiation of hippocampal interneurons. J Neurophysiol 48 : 597-607.

Buzsaki G, Grastyan E, Czopf J, Kellenyi L, Prohaska O (1981) Changes in neuronal transmission in the rat hippocampus during behavior. Brain Res 225:235-247.

Buzsaki G, Leung LS, Vanderwolf CH (1983) Cellular basis of hippocampal EEG in the behaving rat. Brain Res Rev 6:139-171.

Chattarji S, Stanton PK, Sejnowski TJ (1989) Commissural synapses, but not mossy fiber synapses, in hippocampal field CA3 exhibit associative long-term potentiation and depression. Brain Res 495:134 150.

Davies CH, Starkey SJ, Pozza MF, Collingridge GL (1991) $\mathrm{GABA}_{\mathrm{B}}$ autoreceptors regulate the induction of LTP. Nature 349:609-611

Diamond DM, Dunwiddie TV, Rose GM (1988) Characteristics of hippocampal primed burst potentiation in vitro and in the awake rat. J Neurosci 8:4079-4088.

Douglas RM, Goddard GV, Riives M (1982) Inhibitory modulation of long-term potentiation: evidence for a postsynaptic locus of control. Brain Res 240:259-272.

Fraser DD, MacVicar BA (1991) Low-threshold transient calcium current in rat hippocampal lacunosum-moleculare interneurons: kinetics and modulation by neurotransmitters. J Neurosci 11:28122820 .

Freeman JA, Nicholson C (1975) Experimental optimization of current source-density technique for anuran cerebellum. J Neurophysiol 38:369-382.

Frotscher M (1983) Dendritic plasticity in response to partial deafferentation. In: Neurobiology of the hippocampus (Seifert W, ed), pp 65-77. London: Academic.

Frotscher M, Leranth C, Lubbers K, Oertel WH (1984) Commissural afferents innervate glutamate decarboxylase immunoreactive nonpyramidal neurons in guinea pig hippocampus. Neurosci Lett 46:137143.

Gottlieb DI, Cowan WM (1973) Autoradiographic studies of the commissural and ipsilateral association connections of the hippocampus and dentate gyrus of the rat. I. The commissural connections. J Comp Neurol 149:393-422.

Grinvald A, Frostig RD, Lieke E, Hildesheim R (1988) Optical imaging of neuronal activity. Physiol Rev 68:1285-1366.

Gustafsson B, Wigström H (1988) Physiological mechanisms underlying long-term potentiation. Trends Neurosci 11:156-162.

Hesse GW, TJ Teyler (1976) Reversible loss of hippocampal long term potentiation following electroconvulsive seizures. Nature 264 : $562-564$.

Holsheimer J (1987) Electrical conductivity of the hippocampal CA1 layers and application to current-source-density analysis. Exp Brain Res 67:402-410.

Ishizuka N, Weber J, Amaral DG (1990) Organization of intrahippocampal projections originating from CA3 pyramidal cells in the rat. J Comp Neurol 295:580-623.

Kunkel D, Lacaille JC, Schwartzkroin PA (1988) Ultrastructure of lacunosum-moleculare interneurons of hippocampal CAl region. Synapse 2:382-394.

Lacaillc JC, Schwartzkroin PA (1988) Stratum-lacunosum-moleculare interneurons of hippocampal CAl region. I. Intracellular response characteristics, synaptic responses, and morphology. J Neurosci 8:1400-1410.

Lacaille JC, Meuller AJ, Kunkel DD, Schwartzkroin PA (1987) Local circuit interactions between oriens/alveus interneurons and CA1 pyramidal cells in hippocampus: electrophysiology and morphology. $\mathrm{J}$ Neurosci 7:1979-1993.
Lambert NA, Borroni AM, Grover LM, Teyler TJ (1991) Hyperpolarizing and depolarizing $\mathrm{GABA}_{\mathrm{A}}$ receptor-mediated dendritic inhibition in area CAl of the rat hippocampus. J Neurophysiol 66:15381548.

Laurberg S (1979) Commissural and intrinsic connections of the rat hippocampus. J Comp Neurol 184:685-708.

Leung LS (1979) Potentials evoked by the alvear tract in hippocampal CA1 of rats. II. Spatial field analysis. J Neurophysiol 42:1571-1589.

Leung LS (1980) Behaviour dependent evoked potentials in the hippocampal CA1 region of the rat. I. Correlation with behaviour and EEG. Brain Res 198:95-117.

Leung LS (1990) Field potentials in the central nervous systemrecording, analysis and modelling. In: Neuromethods, Vol 15, Neurophysiological techniques. Applications to neural systems (Boulton AA, Baker GB, Vanderwolf CH, eds), pp 313-369. Clifton, NJ: Humana.

Leung LS, Shen B (1991) Hippocampal CAl evoked response and radial 8-arm maze performance after hippocampal kindling. Brain Res 555:353-357.

Leung LS, Shen B (1992) Apical dendritic LTP in CA1 in behaving rats: high-frequency dependent and APV-resistant. Soc Neurosci Abstr 18:1497.

Leung LS, Shen B (1993) Long-term potentiation in hippocampal CA 1: effects of afterdischarges, NMDA antagonists and anti-convulsants. Exp Neurol, in press.

Leung LS, Shen B, Kaibara T (1992) Long-term potentiation induced by patterned stimulation of the commissural pathway to hippocampal CA1 region in freely moving rats. Neuroscience 48:63-74.

Levy WB, Desmond NL (1985) Associative potentiation/depression in the hippocampal dentate gyrus. In: Electrical activity of the archicortex (Buzsaki E, Vanderwolf $\mathrm{CH}$, eds), pp 359-373. Budapest: Akademiai Kiado.

Levy WB, Steward O (1979) Synapses as associative memory elements in the hippocampal formation. Brain Res 175:233-245.

Lomo T (1971) Potentiation of monosynaptic EPSPs in the perforant path-dentate gyrus cell synapse. Exp Brain Res 12:46-63.

Madison DV, Malenka RC, Nicoll RA (1991) Mechanisms underlying long-term potentiation of synaptic transmission. Annu Rev Neurosci 14:379-397.

McNaughton BL (1980) Evidence for two physiologically distinct perforant pathways to the fascia dentata. Brain Res 199:1-19.

Melchers BPC, Lopes da Silva FH, Wadman WJ (1986) Long-term potentiation in the hippocampal slice: spatial aspects. In: Learning and memory: mechanisms of information storage in the nervous system (Matthies H, ed), pp 51-60. Frankfurt: Pergamon.

Muller D, Lynch G (1989) Evidence that changes in presynaptic calcium currents are not responsible for long-term potentiation. Brain Res 479:290-299.

Paxinos G, Watson C (1986) The rat brain in stereotaxic coordinates, 2d ed. San Diego: Academic.

Ranck JB Jr (1973) Studies on single neurons in dorsal hippocampal formation and septum in unrestrained rats. I. Behavioural correlates and firing repertoires. Exp Neurol 41:462-531.

Raisman G, Cowan WM, Powell TPS (1965) The extrinsic afferent, commissural and associational fibers of the hippocampus. Brain 88 : 963-988.

Sastry BR, Goh JW, Auyeung A (1986) Associative induction of posttetanic and long-term potentiation in CA1 neurons of rat hippocampus. Science 232:988-990.

Schwartzkroin PA (1981) To slice or not to slice. In: Electrophysiology of isolated mammalian CNS preparations (Kerkut GA, Wheal HV, eds), pp 15-50. London: Academic.

Schwartzkroin PA (1986) Regulation of excitability in hippocampal neurons. In: The hippocampus, Vol 3 (Isaacson RL, Pribram KH, eds), pp 113-136. New York: Plenum.

Schwartzkroin PA, Kunkel D (1985) Morphology of identified interneurons in the CA1 region of guinea pig hippocampus. J Comp Neurol 232:205-218.

Staubli U, Lynch G (1987) Stable hippocampal long-term potentiation elicited by "theta" pattern stimulation. Brain Res 435:227-234.

Staubli U, Lynch G (1990) Stablc dcpression of potentiated synaptic responses in the hippocampus with $1-5 \mathrm{~Hz}$ stimulation. Brain Res 513:113-118.

Steward O, Tomasulo R, Levy WB (1990) Blockade of inhibition in a pathway with dual excitatory and inhibitory action unmasks a ca- 
pability for LTP that is otherwise not expressed. Brain Res 516:292300.

Swanson LW, Wyss JM, Cowan WM (1978) An autoradiographic study of the organization of intrahippocampal association pathways in the rat. J Comp Neurol 181:681-716.

Tamamaki N, Abe K, Nojyo Y (1988) Three-dimensional analysis of the whole axonal arbors originating from single CA2 pyramidal neurons in the rat hippocampus with the aid of a computer graphic technique. Brain Res 452:255-272.

Taube JS, Schwartzkroin PA (1987) Intracellular recording from hippocampal $\mathrm{CA}_{1}$ interneurons before and after development of longterm potentiation. Brain Res 419:32-38.

Taube JS, Schwartzkroin PA (1988) Mechanisms of long-term potentiation: a current-source density analysis. J Neurosci 8:1645-1655.

Teyler TJ, DiScenna S (1987) Long-term potentiation. Annu Rev Ncurosci 10:131-161.

van Groen T, Wyss JM (1988) Species differences in hippocampal commissural connections: studies in rat, guinea pig, rabbit and cat. $\mathrm{J}$ Comp Neurol 267:322-334.
White G, Levy WB, Steward O (1988) Evidence that associative interactions between synapses during the induction of long-term potentiation occur within local dendritic domains. Proc Natl Acad Sci USA 85:2368-2372.

Wigstrom H, Gustafsson B (1985) Facilitation of hippocampal longlasting potentiation by GABA antagonists. Acta Physiol Scand 125: 159-172.

Yeckel MF, Berger TW (1990) Feedforward excitation of the hippocampus by afferents from the entorhinal cortex: redefinition of the role of the tri-synaptic pathway. Proc Natl Acad Sci USA 87:58325836.

Young AB, Fagg GE (1990) Excitatory amino acid receptors in the brain: membrane binding and receptor autoradiographic approaches. Trends Pharmacol Sci 11:126-133.

Zalutsky RA, Nicoll RA (1990) Comparison of two forms of longterm potentiation in single hippocampal neurons. Science 248:16191624.

Zhao D, Leung LS (1991) Effects of hippocampal kindling on pairedpulse response in CAl in vitro. Brain Res 564:220-229. 